\title{
Analisis Tahanan Pentanahan Kaki Tower SUTT 70 kV Rute Cigereleng-Majalaya
}

\author{
Teguh Arfianto, Adam Ibnu Salam \\ Jurusan Teknik Elektro \\ Institut Teknologi Nasional \\ Bandung, Indonesia \\ Teguh.arfianto@gmail.com, Adamibnu18@gmail.com
}

\begin{abstract}
Abstrak-Pentanahan merupakan salah satu cara proteksi listrik dari gangguan luar ataupun gangguan dalam. Salah satu gangguan yaitu gangguan petir, besarnya tahanan pentanahan kaki tower dapat mengakibatkan tegangan isolator naik yang dapat merusak peralatan dan lain-lain. Oleh karena itu salah satu usahanya yaitu dengan cara membuat sistem pentanahan di kaki tower transmisi dengan nilai pentanahan sekecil mungkin. Dengan didapatkannya hasil perhitungan sehingga dapat menghitung tahanan pentanahan kaki tower maka dapat menganalisa dengan cara membandingkan nilai pengukuran dengan perhitungan. Kaki tower transmisi Cigereleng-Majalaya memakai 9 rod batang yang ditanamkan dan dihubung secara paralel untuk sistem pentanahan. Dengan begitu diharapkan dapat mereduksi tahanan kaki pentanahan dibawah standar yaitu $<5 \mathrm{ohm}$. Banyaknya elektroda rod berjumlah 9 dan di hubung parallel, dapat dilihat dari hasil perhitungan bahwa dari banyaknya tower transmisi cigereleng-majalaya yaitu berjumlah 48 tower, nilai resistansi total sistem paling besar yaitu $3,05 \mathrm{ohm}$ dan yang paling rendah yaitu $1,61 \mathrm{ohm}$. Perbedaan nilai pengukuran dan perhitungan tidak berbeda jauh yaitu hanya $1,09 \mathrm{ohm}$. Hasil ini sangat baik karena di bawah standar maksimal tahanan tanah yaitu $5 \mathrm{ohm}$.
\end{abstract}

Kata-Kunci : Pentanahan, Kaki tower, Rod, Parallel

\section{PENDAhULUAN}

Petir yang menerpa kawat tanah saluran transmisi menimbulkan tegangan lebih surja berupa gelombang berjalan yang merambat dari titik sambaran menuju tower transmisi berikutnya, selanjutnya akan merambat sampai ke pembumian tower tersebut. Adanya perbedaan impedansi surja pembumian tower dengan impedansi surja tower menyebabkan gelombang ini akan dipantulkan kembali ke puncak tower. Kemudian dari puncak tower gelombang tegangan surja dipantulkan lagi ke pembumian tower. Dengan demikian akan terjadi pantulan berulang di pembumian dan puncak tower. Pantulan-pantulan gelombang ini akan membuat tegangan pada isolator tower naik. Dengan memperkecil impedansi pembumian tower maka tegangan surja yang dipikul isolator akan semakin kecil. Untuk memperkecil impedansi surja menara dapat dilakukan dengan memperkecil pentanahan kaki tower [1].

Pentanahan merupakan sistem yang umum digunakan di dunia kelistrikan yang bertujuan mengamankan peralatanperalatan listrik maupun manusia yang berada disekitar gangguan [2], diperlukan pentanahan yang baik pada kakikaki tower. Salah satunya dengan grounding rod yang dapat memperkecil tahanan pentanahan pada kaki tower dengan cara di parallel. Dengan harapan bisa meminimalisir gangguan yang sering terjadi oleh petir salah satunya. Pada dasarnya pentanahan yang baik itu dibawah $5 \mathrm{ohm}$. Untuk itu pentanahan yang baik sangat dibutuhkan agar gardu induk dan jaringan distribusi tetap lancar menyalurkan listrik ke masyarakat dan masyarakat bisa bekerja dengan produktif.

Berbeda dengan artikel yang lain seperti A Case Study on Ground Resistance Based on Copper Electrode vs Galvanized Iron Electrode yang membahas tentang perbandingan elektroda tembaga dengan elektroda galvanis besi untuk system grounding yang lebih baik [3] , implementasi pentanahan grid pada tower transmisi $150 \mathrm{kV}$ ( aplikasi pada tower $150 \mathrm{kV}$ tower 33) yang Membahas tentang penambahan pentanahan grid, dengan menggunakan rumus tahanan grid oleh IEEE std 80-1986 dan menggunakan rumus parallel untuk penggabungan tanahan kaki tower dengan tanahan grid [4] dan Effect Of Grid Parameter Variation On The Performance Of Grounding System yang menjelaskan tentang menganalisis kinerja sistem pembumian dengan berbagai parameter desain grid

[5], Kesempatan kali ini penulis akan membahas Analisa Tahanan Pentanahan Kaki Tower SUTT 70 kV di CigerelengMajalaya. Dengan adanya pentanahan kaki menara Cigereleng-Majalaya dengan jumlah rod elektroda 9 buah dan dihubungkan secara parallel. Maka dari itu penulis akan membandingkan hasil pengukuran dengan perhitungan dari IEEE std 80-2000.Tujuan dari penulisan ini yaitu didapatkan hasil perhitungan tahanan pentanahan dan didapatkan hasil Analisa dengan cara membandingkan nilai perhitungan dengan pengukuran.

\section{TINJAUAN PUSTAKA}

\section{A. Pentanahan}

Pentanahan merupakan salah satu faktor kunci dalam usaha pengamanan (perlindungan) instalasi listrik. Agar sistem pentanahan dapat bekerja dengan efektif, sistem pentanahan harus memenuhi persyaratan sebagai berikut [2]:

1. Membuat jalur impedansi rendah ke tanah untuk pengamanan personil dan peralatan, menggunakan rangkaian yang efektif.

2. Dapat melawan dan menyebarkan gangguan berulang dan arus akibat surja hubung (surge current).

3. Menggunakan bahan tahan korosi terhadap berbagai kondisi kimiawi tanah, untuk menyakinkan kontinuitas penampilannya sepanjang umur peralatan yang dilindungi.

4. Menggunakan sistem mekanik yang kuat namun mudah dalam pelayanan.

Sistem pentanahan yang baik akan memberikan keandalan pada sistem tenaga listrik, disamping keamanan 
yang terjaga pada sistem tenaga listrik juga peralatan lain yang mendukungnya.

\section{B. Jenis-Jenis Pentanahan}

1. Elektroda Batang

Elektroda bentuk batang ini adalah elektroda berbentuk pipa atau batang profil atau logam lain yang ditanamkan tegak lurus ke dalam tanah dengan kedalaman antara 1 sampai 10 meter. Pentanahan ini paling banyak digunakan, karena mepunyai banyak keuntungan apabila dibandingkan dengan menggunakan elektroda lainnya. Adapun keuntungan tersebut adalah harga elektroda ini cukup murah dan mudah didapat, pemasangannya mudah dan tidak memerlukan tempat yang luas. Apabila ditanam sampai pada kedalaman air tanah dengan maksud supaya tahanan pentanahan menjadi rendah. Apabila tahanan dari sebuah elektroda belum cukup rendah, disekitar elektroda yang pertama dapat dipasang elektroda lain yang kemudian dihubungkan secara parallel untuk mendapatkan tahanan pentanahan yang lebih rendah. Makin panjang elektroda batang ditanam dalam tanah, maka tahanan kontaknya terhadap tanah akan semakin kecil karena menurunnya tahanan jenis tanah dan bertambahnya luas permukaan tanah yang terkena elektroda [4].

\section{Elektroda pita}

Elektroda pita adalah elektroda yang dibuat dari penghantar berbentuk pita atau berpenampang bulat atau penghantar pilin yang pada umumnya ditanam secara dangkal. Elektroda ini dapat ditanam secara dangkal pada kedalaman 0,5 sampai 1,0 meter dari permukaan tanah, dan tergantung dari kondisi dan jenis tanah. Elektroda jenis ini sering digunakan pada tempat-tempat yang mempunyai tahanan jenis tinggi, terutama pada tanah yang banyak mengandung batu-batu sejajar dengan permukaan tanah dan elektroda tersebut dihubungkan satu dengan lainnya sehingga membentuk beberapa jaringan [4].

\section{Elektroda Plat}

Elektroda plat adalah elektroda dari plat logam. Pada pemasangannya elektroda ini dapat ditanam tegak lurus atau mendatar tergantung dari tujuan penggunaannya. Bila digunakan sebagai elektroda pembumian pengaman maka cara pemasangannya adalah tegak lurus dengan kedalaman kira-kira 1 meter di bawah permukaan tanah dihitung dari sisi plat sebelah atas. Bila digunakan sebagai elektroda pengatur yaitu mengatur kecuraman gradien tegangan guna menghindari tegangan langkah yang besar dan berbahaya, maka elektroda plat tersebut ditanam mendatar. Pentanahan hantaran netral dengan menggunakan elektroda pelat sudah jarang dipakai karena tidak menguntungkan, sebab harganya terlalu mahal, mudah berkarat dan juga kurang praktis, dimana waktu pengecekan harus digali lobang terlebih dahulu [4].

\section{METODE PENELITIAN}

Alir diagram ini menjelaskan tentang tahapan-tahapan dari mulai studi literature hingga sampai didapatkan kesimpulan dari hasil penelitian.

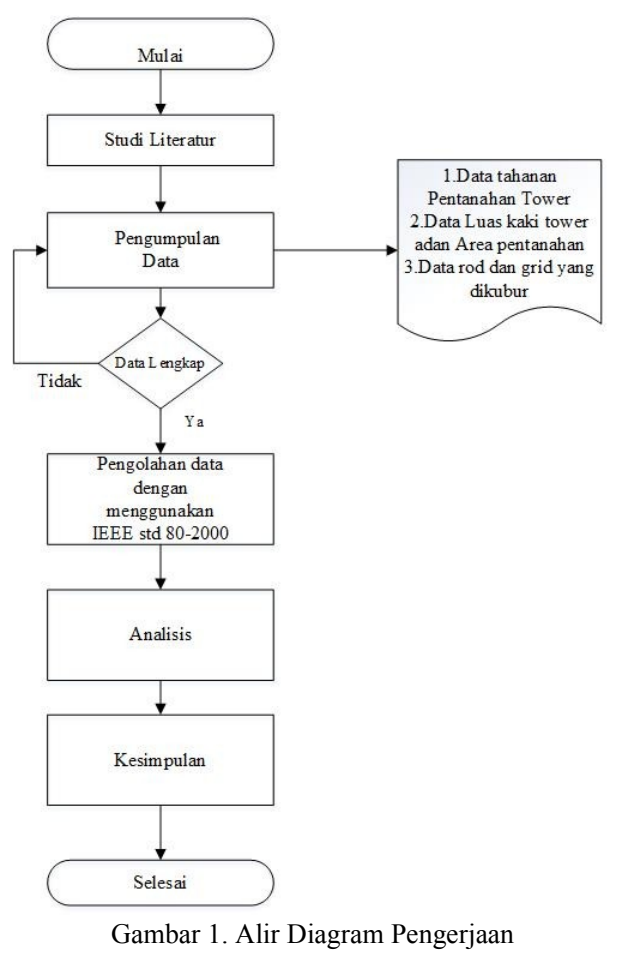

Studi literatur adalah langkah pertama yang harus dilakukan sebelum melakukan penelitian, dikumpulkan referensi dari mata kuliah yang telah diambil, buku pedoman perusahaan, serta beberapa karya ilmiah yang telah melakukan penelitian yang serupa untuk mendukung penyusunan laporan.

Selanjutnya yaitu mengambil data. Data yang dibutuhkan untuk melakukan penelitian sistem pentanahan ini antara lain:

1. Data tahanan tanah tower $70 \mathrm{KV}$ di cigereleng-Majalaya. Data ini akan digunakan untuk mencari nilai tahanan jenis tahan dari persamaan sederhana. Kemudian nilai tahanan jenis tanah ini akan dipakai di persamaan yang lainnya.

2. Data tower $70 \mathrm{kV}$. Data ini digunakan pada persamaan sederhana untuk mencari nilai tahanan grid dengan efek kedalaman grid pada nilai area cakupan pentanahan kawat sekang terhadap grid (A). Selain itu pada persamaan Schwarz's dipakai pada persamaan untuk mencari tahanan tanah dari grid, tahanan tanah rod, dan tahanan tanah bersama antara grid dan batang.

3. Data rod dan grid yang di kubur. Data ini berisi data batang dan grid yang dipakai. Dari nilai panjang rod (LR), diameter rod (b), jumlah rod (nR), jumlah panjang rod yang di kubur $\left(L_{T}\right)$, panjang grid (Lc), kedalaman grid (h) dan diameter konduktor (a). Nilai-nilai tersebut akan dimasukan ke semua persamaan untuk mendapatkan Nilai tahanan pentanahan total system $(\mathrm{Rg})$.

Metoda yang dipakai yaitu dengan cara membandingkan hasil perhitungan dengan hasil pengukuran, kemudian diambil analisa dan kesimpulan. Pertamatama mengumpulkan hasil pengukuran pentanahan kaki tower Cigereleng-Majalaya dan data tower,rod dan lain-lain. Setelah mendapatkan itu semua, masukan nilai-nilai dari data yang didapat yang di butuhkan di rumus- rumus persamaan yang dipakai di IEEE std 80-2000. Ketika mendapatkan hasil dari perhitungan maka selanjutnya dapat dianalisa dan di ambil kesimpulan. 
Langkah-langkah perhitungan yang merujuk pada IEEE std 80- 2000 yaitu :

1. Menghitung tahanan jenis tanah [6].

$$
\rho=\sqrt{\frac{4 R_{g} L_{T}}{\sqrt{\frac{\pi}{A}}}}
$$

Keterangan:

$R_{q}=$ Tahanan $\operatorname{grid}(\Omega)$

$\rho=$ Tahanan jenis tanah $(\Omega . \mathrm{m})$

$A=$ Area cakupan pentanahan kawat sekang terhadap grid $\left(m^{2}\right)$

$L_{T}=$ Total panjang konduktor dan rod yang dikubur (m)

2. Menghitung tahanan grid dengan efek kedalaman grid [6]-[4].

$$
R_{g}=\rho\left[\frac{1}{L_{T}}+\frac{1}{\sqrt{20 A}}\left(1+\frac{1}{1+h \sqrt{\frac{20}{A}}}\right)\right]
$$

Keterangan:

$h=$ Kedalaman grid yang di kubur (m)

3. Menghitung tahanan tanah dari grid [6].

$$
R_{1}=\frac{\rho}{\pi L_{c}}\left[\left(\frac{2 L_{c}}{a^{\prime}}\right)+\frac{k_{1} L_{c}}{\sqrt{A}}-k_{2}\right]
$$

Keterangan:

$L_{c}=$ Total panjang konduktor yang terhubung ke grid (m)

$a^{\prime}=\sqrt{a .2 h}$ jari-jari konduktor yang di kubur kedalaman grid $(\mathrm{m})$

$a=$ jari-jari konduktor (m)

$k_{1}=$ Koefisien 1

$k_{2}=$ Koefisien 2

4. Menghitung tahanan tanah rod [6].

$$
R_{2}=\frac{\rho}{2 \pi n_{R} L_{R}}\left[\left(\frac{4 L_{R}}{b}\right)-1+\frac{2 k_{1} L_{R}}{\sqrt{A}}\left(\sqrt{n_{R}}-1\right)^{2}\right]
$$

Keterangan:

$n_{R}=$ jumlah rod pada area $(\mathrm{m})$

$L_{R}=$ Panjang rod (m)

$b=$ jari-jari rod

5. Menghitung hambatan tanah bersama antara grid dan batang [6].

$$
R_{m}=\frac{\rho}{\pi L_{c}}\left[\left(\frac{2 L_{c}}{L_{R}}\right)+\frac{k_{1} L_{c}}{\sqrt{A}}-k_{2}+1\right]
$$

6. Menghitung tahanan total system [6].

$$
R_{g}=\frac{R_{1} R_{2}-R_{m}^{2}}{R_{1}+R_{2}-2 R_{m}}
$$

Keterangan:

$R_{1}=$ Resistansi tanah dari konduktor grid $(\Omega)$

$R_{2}=$ Resistansi tanah dari semua batang pentanahan $(\Omega)$

$R_{m}=$ Resistensi tanah bersama antara kelompok konduktor grid,R1, dan kelompok batang tanah, R2 $(\Omega)$. menghitung $\mathrm{K} 1$ dan $\mathrm{K} 2$

Untuk kedalaman $h=\frac{1}{10} \times \sqrt{\text { Area }}$

Diketahui $\mathrm{x}=1$ dikarenakan luas kaki pentanahan adalah bujur sangkar.

a. Untuk K1

$y_{B}=-0.005 x+1.20$

b. Untuk K2

$$
y_{B}=0.10 x+4.68
$$

Menghitung jari-jari konduktor yang di terkubur kedalaman grid

$$
a=\sqrt{a \cdot 2 h}
$$

\section{HASIL DAN ANALISIS}

Penelitian ini penulis membahas tentang perbandingan hasil pengukuran dengan hasil perhitungan. Sehingga penulis dapat menyimpulkan bahwa dengan 9 rod dan dihubung parallel tahanan rute Cigereleng-Majalaya baik atau tidak.

\section{A. Hasil Pengukuran}

Tabel 1 menjelaskan hasil pengukuran rata-rata dari seriap kaki $(A, B, C, D)$ di setiap tower.

\begin{tabular}{|c|c|c|c|c|}
\hline \multirow{2}{*}{ Tabel 1. Hasil pengukuran } \\
\cline { 2 - 5 } NO TOWER & \multicolumn{4}{|c|}{ Rata-Rata } \\
\cline { 2 - 5 } & $\mathbf{A}$ & $\mathbf{B}$ & $\mathbf{C}$ & $\mathbf{D}$ \\
\cline { 2 - 5 } $\mathbf{\Omega}$ & $\Omega$ & $\Omega$ & $\Omega$ \\
\hline $\mathbf{1}$ & $\mathbf{2}$ & $\mathbf{3}$ & $\mathbf{4}$ & $\mathbf{5}$ \\
\hline A1 & 0,8 & 0,5 & 0,6 & 1,2 \\
\hline A2 & 1,9 & 1,5 & 1,2 & 1,3 \\
\hline D3 & 1,6 & 1,1 & 0,8 & 1,0 \\
\hline D4 & 1,8 & 1,3 & 1,4 & 0,5 \\
\hline D5 & 1,8 & 1,5 & 1,1 & 0,5 \\
\hline D6 & 2,0 & 1,8 & 1,6 & 1,3 \\
\hline D7 & 1,3 & 1,0 & 1,1 & 0,6 \\
\hline D8 & 1,9 & 1,5 & 1,2 & 1,0 \\
\hline A9 & 0,9 & 1,0 & 0,8 & 1,1 \\
\hline D10 & 1,8 & 1,4 & 1,3 & 1,1 \\
\hline \multirow{2}{*}{ D11 } & 1,2 & 0,8 & 0,9 & 0,8 \\
\hline A12 & 1,5 & 1,2 & 1,2 & 0,2 \\
\hline A13 & 0,6 & 0,7 & 0,7 & 0,4 \\
\hline D14 & 1,5 & 0,9 & 0,8 & 0,5 \\
\hline D15 & 1,3 & 0,7 & 0,6 & 0,2 \\
\hline D16 & 1,3 & 1,2 & 1,0 & 0,7 \\
\hline D17 & 1,3 & 1,0 & 0,9 & 0,6 \\
\hline A18 & 0,9 & 1,0 & 0,8 & 0,7 \\
\hline D19 & 1,5 & 1,0 & 0,9 & 1,5 \\
\hline D20 & 1,5 & 1,2 & 1,0 & 5,7 \\
\hline D21 & 1,9 & 1,8 & 1,7 & 1,0 \\
\hline D22 & 1,9 & 1,8 & 3,0 & 0,9 \\
\hline A23 & 1,4 & 1,5 & 1,4 & 0,8 \\
\hline D24 & 1,5 & 1,4 & 1,3 & 0,8 \\
\hline D25 & 1,3 & 1,1 & 1,2 & 0,2 \\
\hline D26 & 1,2 & 1,0 & 1,7 & 0,9 \\
\hline & & & \\
\hline
\end{tabular}




\begin{tabular}{|c|c|c|c|c|}
\hline \multicolumn{5}{|c|}{ Tabel 1. Lanjutan } \\
\hline 1 & 2 & 3 & 4 & 5 \\
\hline D27 & 0,9 & 0,8 & 1,0 & 1,0 \\
\hline D28 & 1,5 & 1,5 & 1,2 & 1,0 \\
\hline A29 & 1,5 & 1,8 & 1,2 & 0,6 \\
\hline D30 & 1,4 & 1,5 & 1,6 & 0,5 \\
\hline D31 & 1,3 & 1,2 & 1,1 & 0,6 \\
\hline D32 & 1,1 & 0,8 & 1,0 & 1,1 \\
\hline D33 & 1,5 & 1,3 & 1,3 & 1,2 \\
\hline D34 & 1,0 & 0,9 & 0,7 & 1,0 \\
\hline A35 & 0,6 & 0,3 & 0,4 & 2,2 \\
\hline D36 & 1,0 & 0,8 & 1,0 & 2,6 \\
\hline D37 & 0,9 & 0,7 & 0,8 & 1,9 \\
\hline D38 & 1,3 & 1,3 & 1,0 & 0,3 \\
\hline D39 & 0,8 & 0,7 & 0,9 & 1,3 \\
\hline D40 & 1,8 & 1,4 & 1,3 & 1,3 \\
\hline D41 & 0,8 & 0,7 & 0,4 & 0,8 \\
\hline D42 & 1,8 & 1,8 & 1,6 & 0,8 \\
\hline A43 & 1,0 & 0,7 & 0,9 & 0,8 \\
\hline D44 & 2,6 & 2,0 & 1,6 & 1,2 \\
\hline D45 & 1,8 & 1,5 & 1,7 & 1,1 \\
\hline D46 & 2,2 & 1,7 & 1,5 & 0,7 \\
\hline A47 & 1,4 & 0,9 & 0,7 & 1,5 \\
\hline A48 & 1,9 & 1,6 & 1,1 & 1,5 \\
\hline
\end{tabular}

\section{B. Data}

Tabel 2 menampilkan data-data jenis tower, panjang kaki tower, lebar kaki towertinggi tower dan area cakupan pentanahan di rute Cigereleng-Majalaya.

Tabel 2. Data Tower dan Pentanahan

\begin{tabular}{|l|c|c|c|c|}
\hline \multicolumn{1}{|c|}{ Jenis } & $\begin{array}{c}\text { Panjang } \\
\text { Kower } \\
\text { Tower } \\
(\mathrm{m})\end{array}$ & $\begin{array}{c}\text { Lebar } \\
\text { kaki } \\
\text { tower } \\
(\mathrm{m})\end{array}$ & $\begin{array}{c}\text { Tinggi } \\
\text { Tower } \\
(\mathrm{m})\end{array}$ & $\begin{array}{c}\text { Area } \\
\text { Cakupan } \\
\text { Pentanahan } \\
\left(\mathrm{m}^{2}\right)\end{array}$ \\
\hline $\begin{array}{l}\text { Suspensi } \\
\text { on (D) }\end{array}$ & 6 & 6 & 21 & 49 \\
\hline $\begin{array}{l}\text { Tension } \\
(\mathrm{A})\end{array}$ & 8 & 8 & 21 & 81 \\
\hline
\end{tabular}

\section{Pengolahan data}

Pada pengolahan data ini mengambil salah satu contoh nilai rata-rata bersama dari tower A1.

1. Menghitung Tahanan jenis tanah (persamaan 1)

$$
\begin{aligned}
& \rho=\sqrt{\frac{4 \times 0,775 \times 95,144}{\sqrt{\frac{\pi}{81}}}} \\
& \rho=38,7 \Omega . m
\end{aligned}
$$

2. Menghitung Tahanan grid dengan efek kedalamannya ( persamaan 2)

$$
\begin{aligned}
& R_{g}=38,7\left[\frac{1}{95,144}+\frac{1}{\sqrt{20 \times 81}}\left(1+\frac{1}{1+0,25 \sqrt{\frac{20}{81}}}\right)\right] \\
& R_{a}=2,22 \Omega
\end{aligned}
$$

3. Menghitung tahanan tanah dari grid dengan persaamaan Schwarz's (persamaan 3)

$$
\begin{aligned}
& R_{1}=\frac{38,7}{\pi \times 68,144}\left[\left(\frac{2 \times 68,144}{0,069}\right)+\frac{1,195 \times 68,144}{\sqrt{81}}-4,78\right] \\
& R_{1}=2,14 \Omega
\end{aligned}
$$

4. Menghitung tahanan tanah rod (persamaan 4)

$$
\begin{aligned}
& R_{2}=\frac{38,7}{2 \times 3,14 \times 9 \times 3}\left[\left(\frac{4 \times 3}{0,01905}\right)-1+\frac{2 \times 1,195 \times 3}{\sqrt{81}}(\sqrt{9}-1)^{2}\right] \\
& R_{2}=1,97 \Omega
\end{aligned}
$$

5. Menghitung hambatan tanah bersama antara grid dan batang (persamaan 5)

$$
\begin{aligned}
& R_{m}=\frac{38,7}{3,14 \times 68,144}\left[\left(\frac{2 \times 68,144}{3}\right)+\frac{1,195 \times 68,144}{\sqrt{81}}-4,78+1\right] \\
& R_{m}=1,64 \Omega
\end{aligned}
$$

6. Menghitung resistansi total system (persamaan 6)

$$
\begin{aligned}
& R_{g}=\frac{2,14 \times 1,97-1,64^{2}}{2,14+1,97-2 \times 1,64} \\
& R_{a}=1,84 \Omega \\
& \text { Keterangan: }
\end{aligned}
$$

1. menghitung $\mathrm{K} 1$ dan $\mathrm{K} 2$

Untuk kedalaman $h=\frac{1}{10} \times \sqrt{\text { Area }}$ [6]

Diketahui $\mathrm{x}=1$ dikarenakan luas kaki pentanahan adalah bujur sangkar.

Untuk K1 (persamaan 7)

$$
\begin{aligned}
& y_{B}=-0.005 x+1.20 \\
& y_{B}=1,195
\end{aligned}
$$

Untuk K2 (persamaan 8)

$$
\begin{aligned}
& y_{B}=0.10 x+4.68 \\
& y_{B}=4.78
\end{aligned}
$$

2. Menghitung jari-jari konduktor yang di terkubur kedalaman grid

$$
\begin{aligned}
& a^{\prime}=\sqrt{a .2 h} \\
& a^{\prime}=\sqrt{0,009525.2 \times 0,25}=0,06901
\end{aligned}
$$

\section{Hasil Perhitungan}

Tabel 3 menampilkan hasil perhitungan dimana setiap kaki nilainya berbeda-beda. Terdapat nilai dari perhitungan tahanan jenis tanah, tahanan grid, tahanan rod, tahanan bersama dan tahanan total system.

\section{E. Analisis}

Banyaknya elektroda rod berjumlah 9 dan di hubung parallel, dapat dilihat dari hasil perhitungan bahwa nilai resistansi total sistem di bawah 3,05 ohm. Hasil ini sangat baik karena di bawah standar maksimal tahanan tanah yaitu $5 \mathrm{ohm}$.

Pebandingan nilai perhitungan tahanan total system dengan nilai rata-rata pengukuran bersama nilai terjauh yaitu 1,09 ohm. Nilai pengukuran lebih kecil dari pada nilai perhitungan dapat dikarenakan ketika pengukuran dilaksanakan ketika tanah sedang basah sehingga tahanan jenis tanah menurun dan tahanan system pun ikut menurun.

Perhitungan dapat dilihat bahwa semakin besar tahanan jenis tanah maka semakin besar nilai tahanan totalnya. Hasil ini sejalur dengan rumus yang digunakan karena nilai tahanan jenis tanah di semua rumus dipakai di pembilang.

Nilai tahanan jenis tanah secara perhitungan pada kaki A1 lebih besar dari pada kaki D3, sedangkan nilai tahanan total system A1 lebih kecil dari pada D3. Nilai tersebut sangat di pengaruhi oleh area cakupan pentanahan, A1 lebih beasar dari paa D3. Semakin luas area cakupan pentanahan, maka tahanan jenis tanahnya semakin besar, dan tahanan totalnya akan lebih kecil dibandingkan tahanan total dari area cakupan pentanahan yang lebih kecil karena pada 
rumus-rumus yang mencari tahanan total system area cakupan pentanahan (A) menjadi pembagi.

\begin{tabular}{|c|c|c|c|c|c|c|}
\hline \multirow{3}{*}{ NO TOWER } & \multicolumn{6}{|c|}{ Tabel 3. Hasil Perhitungan } \\
\hline & $\rho$ & $R_{g}$ & $R_{1}$ & $R_{2}$ & $R_{m}$ & $R_{g s}$ \\
\hline & $\Omega . m$ & $\Omega$ & $\Omega$ & $\Omega$ & \begin{tabular}{l|l}
$\Omega$ & \\
\end{tabular} & $\Omega$ \\
\hline A1 & 38,704 & 2,22 & 2,14 & 1,97 & 1,64 & 1,84 \\
\hline A2 & 53,17 & 3,05 & 2,95 & 2,71 & 2,26 & 2,53 \\
\hline D3 & 37,64 & 2,71 & 2,62 & 2,12 & 2,00 & 2,10 \\
\hline D4 & 40,01 & 2,88 & 2,79 & 2,25 & 2,13 & 2,23 \\
\hline D5 & 39,45 & 2,84 & 2,75 & 2,22 & 2,10 & 2,20 \\
\hline D6 & 45,96 & 3,31 & 3,20 & 2,59 & 2,44 & 2,56 \\
\hline D7 & 35,42 & 2,55 & 2,47 & 1,99 & 1,88 & 1,98 \\
\hline D8 & 42,25 & 3,04 & 2,94 & 2,38 & 2,24 & 2,36 \\
\hline A9 & 42,63 & 2,45 & 2,36 & 2,17 & 1,81 & 2,03 \\
\hline D10 & 42,25 & 3,04 & 2,94 & 2,38 & 2,24 & 2,36 \\
\hline D11 & 34,10 & 2,45 & 2,38 & 1,92 & 1,81 & 1,90 \\
\hline A12 & 44,62 & 2,56 & 2,47 & 2,27 & 1,89 & 2,12 \\
\hline $\mathrm{A} 13$ & 34,20 & 1,96 & 1,89 & 1,74 & 1,45 & 1,63 \\
\hline D14 & 34,47 & 2,48 & 2,40 & 1,94 & 1,83 & 1,92 \\
\hline D15 & 29,93 & 2,15 & 2,08 & 1,68 & 1,59 & 1,67 \\
\hline D16 & 36,70 & 2,64 & 2,56 & 2,07 & 1,95 & 2,05 \\
\hline D17 & 34,83 & 2,51 & 2,43 & 1,96 & 1,85 & 1,94 \\
\hline A18 & 40,35 & 2,32 & 2,24 & 2,05 & 1,71 & 1,92 \\
\hline D19 & 39,37 & 2,83 & 2,74 & 2,22 & 2,09 & 2,20 \\
\hline D20 & 54,56 & 3,92 & 3,80 & 3,07 & 2,90 & 3,04 \\
\hline D21 & 45,16 & 3,25 & 3,15 & 2,54 & 2,40 & 2,52 \\
\hline D22 & 49,10 & 3,53 & 3,42 & 2,76 & 2,61 & 2,74 \\
\hline A23 & 49,79 & 2,86 & 2,76 & 2,53 & 2,11 & 2,37 \\
\hline D24 & 39,81 & 2,86 & 2,77 & 2,24 & 2,12 & 2,22 \\
\hline D25 & 34,93 & 2,51 & 2,43 & 1,97 & 1,86 & 1,95 \\
\hline D26 & 39,09 & 2,81 & 2,72 & 2,20 & 2,08 & 2,18 \\
\hline D27 & 34,19 & 2,46 & 2,38 & 1,92 & 1,82 & 1,91 \\
\hline D28 & 40,72 & 2,93 & 2,84 & 2,29 & 2,16 & 2,27 \\
\hline A29 & 49,45 & 2,84 & 2,74 & 2,52 & 2,10 & 2,35 \\
\hline D30 & 39,65 & 2,85 & 2,76 & 2,23 & 2,11 & 2,21 \\
\hline D31 & 36,53 & 2,63 & 2,54 & 2,06 & 1,94 & 2,04 \\
\hline D32 & 35,74 & 2,57 & 2,49 & 2,01 & 1,90 & 1,99 \\
\hline D33 & 41,19 & 2,96 & 2,87 & 2,32 & 2,19 & 2,30 \\
\hline D34 & 34,00 & 2,45 & 2,37 & 1,91 & 1,81 & 1,90 \\
\hline A35 & 41,36 & 2,38 & 2,29 & 2,11 & 1,76 & 1,97 \\
\hline D36 & 41,34 & 2,97 & 2,88 & 2,33 & 2,20 & 2,31 \\
\hline D37 & 36,83 & 2,65 & 2,57 & 2,07 & 1,96 & 2,05 \\
\hline D38 & 35,20 & 2,53 & 2,45 & 1,98 & 1,87 & 1,96 \\
\hline D39 & 34,05 & 2,45 & 2,37 & 1,92 & 1,81 & 1,90 \\
\hline D40 & 42,74 & 3,07 & 2,98 & 2,41 & 2,27 & 2,38 \\
\hline D41 & 29,07 & 2,09 & 2,02 & 1,64 & 1,54 & 1,62 \\
\hline D42 & 43,80 & 3,15 & 3,05 & 2,47 & 2,33 & 2,44 \\
\hline $\mathrm{A} 43$ & 40,35 & 2,32 & 2,24 & 2,05 & 1,71 & 1,92 \\
\hline D44 & 48,61 & 3,50 & 3,39 & 2,74 & 2,58 & 2,71 \\
\hline D45 & 44,02 & 3,17 & 3,07 & 2,48 & 2,34 & 2,46 \\
\hline D46 & 44,16 & 3,18 & 3,08 & 2,49 & 2,35 & 2,46 \\
\hline A47 & 46,84 & 2,69 & 2,60 & 2,38 & 1,99 & 2,23 \\
\hline A48 & 54,29 & 3,12 & 3,01 & 2,76 & 2,31 & 2,58 \\
\hline
\end{tabular}

\section{KESIMPULAN}

1. Banyaknya jumlah elektroda rod 9 buah dan di hubung parallel, maka nilai perhitungan tahanan kaki pentahanan yang di dapatkan yaitu di bawah standar yaitu $<5 \mathrm{ohm}$. Dengan begitu pentanahan kaki tower CigerelengMajalaya baik dan aman.

2. Nilai perhitungan tahanan terendah di kaki tower D41 dengan nilai resistansi $1,610 \mathrm{hm}$, sedangkan nilai tertinggi berada pada kaki tower D20 dengan nilai resistansi 3,04 ohm.

3. Nilai standar deviasi dari perhitungan yaitu $0,2988 \mathrm{ohm}$ dan nilai standar deviasi dari pengukuran yaitu 0,34327 ohm.

4. Area cakupan pentanahan sangat mempengaruhi nilai tahanan total dan tahanan jenis tanah pada perhitungan. Semakin luas area maka semakin besar tahanan jenis tanah, tapi nilai pentanahannya akan menjadi kecil karena semakin jauh jarak antar elektroda rod makan semakin kecil tahanan total.

5. Perbedaan hasil perhitungan persamaan sederhana dan persamaan scwarz's tidak lebih dari 1 ohm, maka 2 persamaan ini tidak bernilai jauh. Meskipun hasil perhitungan persamaan sederhana lebih besar dari pada persamaan schwarz's, tapi tetap di bawah standar yaitu $<$ $5 \mathrm{ohm}$.

\section{UCAPAN TERIMA KASIH}

Terimakasih kepada PT. PLN (persero) Gardu induk area Majalaya yang telah membantu kelancaran pembuatan laporan ini, sehingga terencana dengan baik dan lancar.

\section{DAFTAR PUSTAKA}

[1] Dabalok, Renhat \& Syahrawardi. (2013). Pengaruh Impedansi Pembumian Menara Transmisi Terhadap Distribusi Tegangan Surja Pada Tiap Menara Transmisi. Univesitas Sumatra Utara. Medan.

[2] Saputra, Nurcahyo H. 2016. Analisis Pentanahan Kaki Menara Transmisi $150 \mathrm{KV}$ Rembang-Blora Bertahanan Tinggi Dan Usaha Menurunkannya. Laporan Skripsi Jurusan Teknik Elektro. Universitas Muhammadiyah Surakarta. Surakarta.

[3] Arfan, Ahmad dkk.2014.A Case Study on Ground Resistance Based on Copper Electrode vs. Galvanized Iron Electrode.

[4] Darmana, Ija dkk. 2016. Implementasi Sistem Pentanahan Grid Pada Tower Transmisi 150 KV (Aplikasi Pada Tower

SUTT $150 \mathrm{KV}$ Toweer 33). Univeritas Bung Hatta Padang. Padang.

[5] Kumar, Anup dan Prasanna.D.Bharadwaj. 2015. Effect Of Grid Parameter Variation On The Performance Of Grounding System.

[6] IEEE std. 80. 2000. IEEE Guide For Safety In Ac Substation Grounding. USA. 